\title{
Semantic Analysis: Can MD\&A Word Choice Increase Stock Price of American Publicly Traded Banks Disseminating Using Twitter?
}

Daniel H. Boylan. Purdue University, Fort Wayne, USA, boyland@pfw.edu

Mathew Thomas. Widener University, USA, mthomas@widener.edu

Evidence Matangi. Purdue University, West Lafayette, Zimbabwe, ematangi@purdue.edu

Marni Brown. University of North Georgia, USA, marni.brown@ung.edu

\begin{abstract}
Social media has become a part of the International framework. Use has risen exponentially and organizations that have relied on traditional channels of communication are considering its use. Researchers studied the impact of semantics on organizations disseminating financial information using Twitter. This study sought to understand the impact of word strength in communicating with investors. This study included 34 American publicly traded banks over four quarters or a sample size of 136 . Seventeen used Twitter while seventeen did not. The researchers analyzed the semantic content of these messages. Using a predictive model, researchers compared the cumulative abnormal returns associated with the announcement. Researchers concluded that using Twitter did not positively impact stock price. Researchers also found that banks using Twitter used more powerful words in communicating. This research advances understanding the role social media and semantics can play to disseminate financial information.
\end{abstract}

Keywords: social media, semantics, event study, market efficiency, cumulative abnormal returns 


\section{INTRODUCTION}

Understanding the use of technology to disseminate financial information can benefit both the technology and financial disciplines. Time and expertise often limit an organization's ability to understand how to disseminate information (Boylan \& Boylan, 2017). Organizations have several traditional sources to communicate results. These include newspapers such as The New York Times, professional financial third-party intermediaries like Prudential and online financial services such as Bloomberg Finance. Organizations are concerned whether their message is properly redisseminated and if they are missing an audience (Luftman et al., 2017). Today, technology innovations have provided opportunities to communicate that have previously not been available (Kivimaa \& Kern, 2016).

In 2013, the Securities and Exchange Commission (SEC) issued a report allowing companies to use social media to report some company news. The law outlining this use is called Regulation Fair Disclosure (RegFD). Companies are no longer limited by the traditional press-releases to disclose information. Organizations can now provide real-time information to more aggressively reach shareholders by engaging social media (Securities and Exchange Commission, 2013).

Historically, investors responding to information the fastest had an advantage. By nature, trading securities is often a race to find investments with a higher value than the person selling determines. Reasons why this difference occurs include new information that has not been built-in, timing differences, or knowledge of future corporate activities (Menkveld, 2011).

Today, with trading happening in milliseconds, the new frontier is not built on speed, but on the quality of information (Boylan, 2016). The Report of Technology trends in the Financial Markets: A 2020 Vision identifies several future trends: the use of predictive analytics or the ability to program trading using algorithms, the use of big data that can cast an even bigger and wider network to connect markets to opportunities, the use of semantics to quantify qualified information, and the use of causation that investigates predictable cause and effect links to look at possible gaps in market prices (Cliff et al., 2011). This research looks only at the third item above, the use of semantics to analyze information. 
There is nothing new about studying the stock price and market change, measuring sentiment analysis, and reactions to financial disclosures. The gap in the research involves the ability to employ the social media platform Twitter to combine these three functions. Work done on this subject is inadequate. A brief search on the Purdue Libraries website on October 4, 2017 using "Twitter" and "stock price" in the search engine, found that there were only four related articles.

Increased bank competition forces executives to enact policies to be more ambitious. One strategy is for an organization to maximize the impact of financial disclosures with both increased audience size and enhanced message content (Boylan \& Boylan, 2017). Organizations can either embrace future disclosure needs or continue with their current process. Rather than guess the effect of disclosures, organizations should decide how to disseminate better, otherwise; they will be forced to react to market changes (Firth et al., 2015).

Technology drives the financial industry. This is true for several reasons, including: speed, communication, competition, organization size, and product complexity (Kivimaa \& Kern, 2016). Organizations understand providing fast and useful information encourages investors to trust them and creates relevance. This communication is also especially important in times when market values are volatile (Thornton, 2015).

A problem is the lack of understanding of how innovative technology can impact shareholder value, including the use of semantics and Twitter to aid financial dissemination. This research aims to add to the body of knowledge on financial dissemination by investigating the use of Tweets, communication word count, and the semantics of the communication. By analyzing the quality of Tweets, one is reminded of the importance of releasing quality information. Current research has not applied Twitter use and sentiment analysis on investment data. This study is guided by the following research question: Can MD\&A word choice increase the stock price of American publicly traded banks using Twitter?

The remainder of this work is organized into the following four sections. First, there is a literature review looking at prior literature that informs this study. The next section includes methodology, including both the research question and experiment design. The third section includes the research findings. Finally, the research ends with conclusions, including limitations and future research. 


\section{LITERATURE REVIEW}

Firms communicate in many ways. Some communications are broad in approach with the use of logos and commercial advertising, while other communications target a specific audience such as stakeholders and community members. Communicating financial results to investors and stockholders is no different. Executives understand that financial disclosures, reports, and footnotes need to be understood by shareholders and investors (Adams, 2017).

Financial markets are important because many people seek information to protect or increase their investments. Financial news and information are available from many different sources. The volume of information is growing exponentially as both communications patterns and data increases (Li et al., 2014). Historically, typical investors receive information from a broker via a fee-based recommendation (Li et al., 2014).

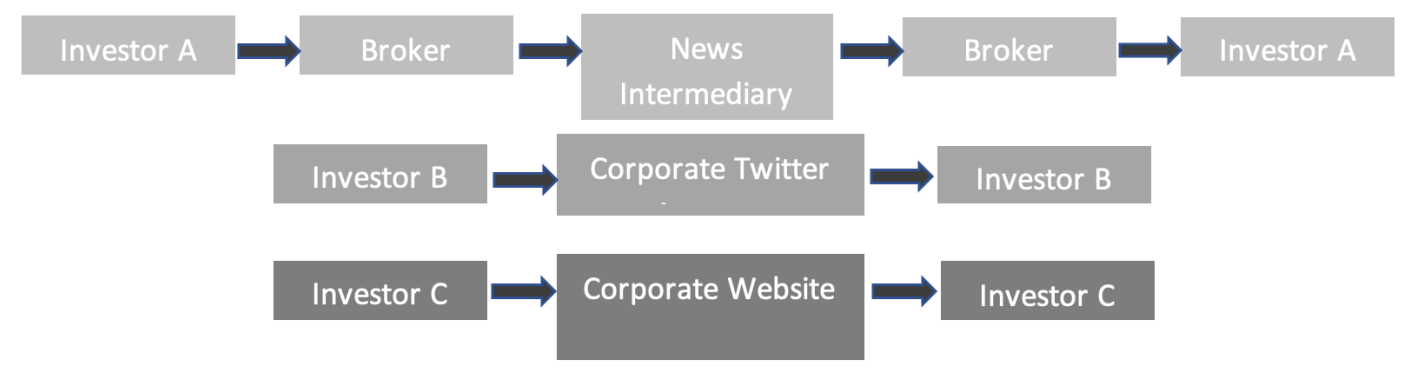

Figure 1. shows the relationship between various investors and different corporate dissemination methods

Corporations routinely deliver financial information, management analysis, notes, disclosures, and clarifications using many sources. Some of these sources include print media, electronic media, and human contact. The fate of an organization's stock price is determined by satisfying shareholders (Aureli, 2017), shown by the increase or decrease in share price of the stock (Feldman et al., 2010).

Third-party news services and financial firms have controlled the information provided based on information given to them from the organization. News organizations, based largely on profitability, became the basis for disseminating information. Some of these third-party sources include print media like the Associated Press, Forbes, The Wall Street Journal, and The New York Times. 
Other electronically oriented media sources include Bloomberg, Yahoo Finance, Reuters, and the Financial Times (Schumaker \& Chen, 2009).

The SEC mandates that publicly traded organizations regularly disseminate a minimum amount of financial detail. Individuals owning shares and other interested parties are required to receive this information (SEC Clarifies, 2011). The data is to inform investors on how the firm's operations are performing and of the resulting impact on the financial statements (Loughran \& McDonald, 2014).

Form 10-K and Form 10-Q are important reports for corporations to use in the disclosure of company information. 10-Q is completed every three months, or quarterly, while the $10-\mathrm{K}$ is annual. These forms provide various information aimed at giving a snapshot of entity performance. This includes: the organization's business, risks, operating results, financial results and a discussion of what is driving the organization. The dependence readers have on these forms means corporations must include "full disclosure" of their operations, follow a set order of topics, and refrain from misleading statements (SEC, 2013) but does not dictate the language an organization uses to communicate. This communication includes how readable the document should be and how comprehensible the content is (Loughran \& McDonald, 2014). Since readers depend on financial disclosures, The Sarbanes-Oxley Act requires both the CEO and the CFO to certify documents as accurate (Boylan, 2016).

As social media use has increased, so has interest in communicating financial results. After years of forbidding this communication, the SEC issued a law named Regulation Fair Disclosure or RegFD for short, in August 2000. The law sought to "level the playing field" for investors, both big and small, by requiring companies to disclose material information at the same time for everyone interested. This restricted large investors from receiving preferential treatment on information as an unfair advantage. In 2008, a release by the SEC (SEC Release No. 34-58288), provided for organizations to use their website for disclosure. Because of investors' requests, on April 2, 2013 the SEC (SEC Release No. 69279) allowed the use of social media to communicate this information (SEC Clarifies, 2013).

One challenge to using social media for dissemination is that the practice is new and not understood ( $\mathrm{Li} \& \mathrm{Li}, 2014)$. Because of many organizations lacking proficiency in social media, the National Investor Relations Institute suggested to 
members that each company should consider their unique situation before deciding use of social media (Morgan, 2013). Though the use of social media could be an opportunity to reach more investors, proper training of employees and a deeper understanding of the impact of such communication needs understanding (Morgan, 2013). Although good news has an impact on stock price, the frequency, volume, and word choice have not been studied. Understanding the reaction to the content of the message is important as investing can be emotional (Bollen et al., 2011).

\subsection{Information Richness}

Investors do not view all information equally. Rich information includes the communication investors feel is more valuable. Less rich information includes communications investors are not as concerned about discovering. The Form 10$\mathrm{K}$ has multiple sections and investors consider some sections more valuable than others. Investors often ignore the Business Description, the Legal Proceedings and "canned information." "Canned information" includes messaging that is similar quarter after quarter. Investors consider the MD\&A the most important section in the Form 10-K (Loughran \& McDonald, 2011).

Investor sentiment is traditionally measured through the feelings and reaction to financial news. High investor sentiment improves the willingness to purchase stock, thus driving prices up (Firth et al., 2015). It is important to understand that stock markets, like the NYSE and NASDAQ, are deemed efficient in incorporating new information into stock prices. Assuming there are inefficiencies provides room to study the reaction of disseminated information on a stock's price.

Studies have looked into the marketing of corporate information and what "skills" of communicating may have the best effect on an organization. Skill refers to the notion that companies who effectively communicate results having a higher share price than those that are either ineffective or do not communicate at all (Groysberg \& Slind, 2012). Research by Jiang (2011) found that in the Chinese stock market, investor sentiment did impact the stock price. When good news was disseminated, the stock increased in price. Alternatively, bad news results in a decrease in the stock price. 
In other research, it was determined that analyzing social media predicted stock prices. The analysis showed the relationship between financial disclosures and changes in stock prices. Public sentiment played an important role on in the changes of stock (Bollen et al., 2011). A study closely related to Bollen's work, classified messages on two message boards, Yahoo!Finance and Raging Bull compared the effects of the messages to the stock prices of companies represented in the Dow Jones Industrial Average. This research benefits from the ability to make an obvious impact of dissemination on stock trades (Sprenger et al., 2014).

\subsection{Modern Dissemination}

Though popular media and Internet sites enthusiastically embrace the topic, roughly seventy percent of organizations do not use social media to disseminate financial results. Many of these organizations are, however, using social media in other ways, including marketing, public relations, and employment purposes (Jung et al., 2018).

Investor expectations will help decide if pro-social media financial dissemination policies will advance. The changing face of the investor will eventually increase the use of social media. As investors older than 65 (with a social media presence of 33 percent) diminish, investors under the age of 40 (with a social media presence of 70 percent), will expect platforms consistent with how they access other information. One survey found $56 \%$ of investors getting the financial results disseminated to them clicked on the link to read the information released (Charlier, 2013).

Many executives want to leverage their disseminations to increase impact. What this means is a company releases information the users can co-create. By cocreating, these people routinely share information via "Retweets," blogs or posts (Aureli, 2017). This behavior magnifies the power of the original message (Thoring, 2011).

When considering the advantages social media provides, strengthening investor relations and loyalty are especially significant (Johnson \& Grimm, 2010). Organizations can meet stakeholder demands by addressing claims through the fostering of two-way exchanges of communication (Orlitzky et al., 2003). Corporations can economically disseminate information without specifically asking anything in return. 
Social media has three dimensions of engagement when considering financial disclosures: cognitive engagement, relational engagement, and behavioral engagement. Cognitive engagement is the degree to which individuals become involved intellectually in the information they read. Relational engagement involves how connected an individual feels to the organization. Behavioral engagement is a reflection on participation with the organization (Li et al., 2014).

Twitter is popular among users and organizations with over 145 million daily users and 750 million Tweets a day (Internet Live Stats, 2020). Many corporations understand this and use Twitter to release information found on their other websites and Tweet information like shareholder meetings. Some public relations specialists have put into place or are considering dedicated Twitter accounts specific to communicating financial results (Alexander \& Gentry, 2014).

Using the Twitter platform is not new, using the technology for financial dissemination is. In this case, organizations can Tweet up to 280 characters. This means they can provide a link for users to gather information (Alexander \& Gentry, 2014; Blankespoor et al., 2014). Users can Retweet the information, thus multiplying the impact (Thoring, 2011). Another advantage of Twitter is the capacity of the platform to publish information in near-real-time (Smailović et al., 2014). Understanding the effect of words in corporate communications enhances the body of knowledge in this area.

Tracking the power of words has become an important research topic in the last several years. This fact has been especially true for Twitter feeds (Bollen et al., 2011). A goal of content analysis is to objectively weigh a delivered message. For many financial applications, the goal is to analyze the relationship between market reactions and the quantified tone of information. Researchers have found a correlation between the quantified tone and individual stock price (Sprenger et al., 2014).

\subsection{Defining Semantics}

Message readability is hard to measure as word connotations constantly change. The difficulty of defining word legibility has not stopped the industry from flourishing and the process of evaluation is growing at a fast rate (Loughran \& McDonald, 2014). 
Every day, millions of social media communications are posted. Identifying what communications mean adds value. Semantic analysis is one tool that can help detect the sentiment in these communications so the posts can be useful (Thelwall et al., 2010). Semantics is the process of evaluating the strength of words used to communicate. Using semantics to quantify subjective information helps discover the strength or weakness of comparative statements (Narayanan et al., 2013). By analyzing the mood of the topic, positive, negative, or between, organizations can actively intervene and work to communicate in a manner best for their message (Berger, 2011).

Semantics as a relatively new field in modern information management, so far, has not developed a common language of its own. According to Liu (2012), some of the most common names to describe semantics include affect analysis, emotion analysis, ontological analysis, opinion extraction, opinion mining, review mining, sentiment analysis, sentiment mining, and subjectivity analysis. In fact, the terms used will differ based on whether referred by academics or industry. For academics, the common phrase is either sentiment analysis, computational linguistics, or opinion mining (Loughran \& McDonald, 2011); while for the industry, the common phrases are sentiment analysis, content analysis, and natural language processing (Liu, 2012).

Taboada et al. (2011) note semantic analysis is also intended to provide a measure of strength or power. This additional value assessment is intended to measure the strength of the word choice against the sender's intent. In general, semantic analysis tries to quantify the message sender's background and attitude (Taboada et al., 2011).

Words are important to investors. For example, the word "million" would normally be considered better than the word "thousand." To see how an organization might use more powerful words to send a message, one could look at the Hudson Bank first quarter Form 10-Q. In this document a more powerful statement is made "with very little appetite for reinvesting" rather than a simpler statement of "we will not reinvest."

Semantics has critics. The task of analyzing sentiment is difficult. The reason is that ranking human emotions is difficult. Research shows if a sentiment analysis tool were deemed accurate, about twenty percent of the time there would be disagreement on the conclusion (Danielsoper, 2019). 


\subsection{How does Semantics Work?}

The origins of semantic analyses are uncertain. Semantics has evolved overtime. An early example can be seen from the philosopher Plato. In his Cratylus dialogue, Plato "named" his nouns as either a person, an object, or an action (Jowett, 1875). As speech sophistication has developed, so has the need to analyze that speech. This development occurs because a word does not have meaning on its own but needs a human to give the word value.

Textual analysis is quantifying of message readability. This means researchers can determine the impact of communications. Word strength or "power" is established by assigning a numerical value (Thelwall et al., 2010). The effectiveness of semantics is based on how well the sender and receiver agree on the strength of the word (Ogneva, 2010). Many analytical tools exist for word content, including the Loughran and McDonald Financial Sentiment Dictionary, Harvard IV-4 Psychological Dictionary by General Inquirer, Lexicoder Sentiment Dictionary, WordStat Sentiment, SAS Text Analytics, Soper Sentiment Analyzer, and Sentiment32 Sentiment Dictionary.

With advancing technology, social media has become a source of information for individuals making decisions on financial institutions (Cwynar et al., 2019). Only recently has semantics been considered a mainstream movement. Before the year 2000 , there was little formal research on the topic. The surge in popularity is a result of several scenarios. First, advanced statistical packages can handle large quantities of data. Second, their wide application in many different fields of study has encouraged a great number of groups to study together. Third, semantic analysis is reliant on large volumes of data. Fourth, the great number of websites and social media platforms has made data access more readily available (Liu, 2012). Last, because of a growing number of Web based ratings, recommendations, and reviews, organizations have a need to understand them to manage their reputations and market products (Wright, 2009). By combining advanced statistical analysis and academic collaboration, it is now possible to address research that was previously unavailable (Liu, 2012).

Today, two areas of semantic analysis exist: the lexicon and text classification approach. The lexicon approach breaks a document down by words or phrases. A statistical measure of the document analyzed is rated based on its power or 
strength. The text classification approach involves learning the sentiment value of previous statements to build a machine learning model (Taboada, et al., 2011).

The financial industry also has an interest in applying semantic knowledge. The industry is known for organizations constantly seeking a competitive advantage. Whether it is seeking information to educate clients or information to predict markets, any advantage in this competitive environment is worthy of consideration. Applications of its use include the search for financial and performance information which reveal investor reactions to changes in market conditions (Boylan \& Boylan, 2017).

In fact, the entities in this study recognize the reliance readers have on their communications. The first section of the MD\&A often is a "Cautionary notice about forward-looking statements." These statements recognize the possible reliance or over reliance on the statements the organizations make about possible future outcomes (Boylan, 2016).

\section{METHODOLOGY}

Financial theory suggests capital markets reflect all available information about a company. This methodology allows researchers the ability to determine the economic effects of the measured variables. As a result, the firm's stock price reflects all information generated about the organization. Scholars developed the "event study methodology to analyze the strength of this reaction. Event studies that look at stock price returns quantify the results by using a requirement of "cumulative abnormal returns" or compounded returns above the expected to measure.

Researchers are looking to see if significant abnormal returns exist during the period studied. If these differences exist, the validity of the semi-strong format of the Efficient Market Hypothesis, with respect to this event, can be questioned. This would mean markets are not quickly absorbing the information or sluggish trading is taking place. This allows researchers to provide an evidence-based recommendation on the release of information (Kamara et al., 2018).

When using the Twitter platform to disseminate financial information, the Tweet is part of the formal release. This research includes the impact of sentiment on those communications. Using the Form 10-K and Form 10-Q from publicly traded American banks, the Management Discussion and Analysis (MD\&A) was 
extracted and analyzed. Understanding how the words used by executives impacts readers of financial statements is important for all accounting and technology professionals. The independent variables include the use of social media and word choice analyzed using semantic analysis software. The dependent variable is the change in shareholder value as determined by the rise and fall in stock price.

The basis of this research is whether the sentiment expressed in financial disclosures on Twitter will impact the organization's stock price. This work contributes to the knowledge of Twitter, sentiment analysis and towards better understanding of phenomena in financial stock markets. Lexicons are normally used to discover the strength of the words an author uses. This study researches the relationship between word strength and stock price.

\subsection{Research Question}

This research has the following research question: "Can MD\&A word choice increase the stock price of American publicly traded banks using Twitter?" Two sets of independent variables compared the use of semantics on the dependent variable of stock price. The null hypothesis, $\mathrm{H}_{0}$, is that external events have no impact on the returns or that the use of semantics will not increase shareholder value. This question was measured using two semantic analysis analyzers.

The null hypothesis $\left(\mathrm{H}_{\mathrm{o}}\right)$ is that: semantic impact of Twitter disseminations does not affect shareholder value. Using the Soper Sentiment Analyzer, the formula reads: $\mathrm{H}_{\mathrm{o}}$ based on sentiment analysis - Soper Sentiment Analyzer or:

$$
\mathrm{H}_{\mathrm{o}}: \mathrm{MT}_{\text {Soper }}=\mathrm{MN}_{\text {Soper }}
$$

and for the Sentiment32 Sentiment Dictionary:

$$
\mathrm{H}_{\mathrm{o}}: \mathrm{MT}_{32}=\mathrm{MN}_{32}
$$

Conversely, the alternative hypothesis $\left(\mathrm{H}_{\mathrm{a}}\right)$ is that: semantic impact of Twitter disseminations does affect shareholder value. Using the Soper Sentiment Analyzer, the formula reads: $\mathrm{H}_{\mathrm{a}}$ based on sentiment analysis - Soper Sentiment Analyzer or:

$$
\mathrm{H}_{\mathrm{a}}: \mathrm{MT}_{\text {Soper }}>\mathrm{MN}_{\text {Soper }}
$$

and for the Sentiment32 Sentiment Dictionary:

$$
\mathrm{H}_{\mathrm{a}}: \mathrm{MT}_{32}>\mathrm{MN}_{32}
$$




\subsection{Event Study}

This research is an event study. It analyzes stock price changes of financial institutions for multiple time periods using cumulative abnormal price returns. This study uses a market model methodology to ensure stock price changes are directly related to financial dissemination (Rango et al., 2015). A Cumulative Abnormal Return (CARs) method was engaged to measure the change in stock price both before and after the "trigger event." For this research, the trigger event was the dissemination of the financial statements. The "event window" is the three days following the "trigger event." This comparison was done for the three days preceding the Twitter announcement and the three days following the announcement. Two data sets were developed. Since earning releases are prescheduled and available to the public, the dates of the releases are known. One set was stock price changes three days before the release. The other set to be analyzed includes the stock price changes for the three days following financial dissemination. The event window is graphically communicated in Figure 2.

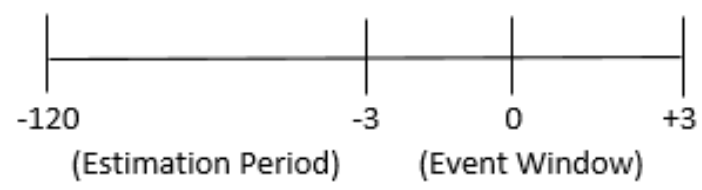

Figure 2. Dissemination timeline including estimation period and event window

Figure 2. displays the timeline showing both Estimation Period of financial performance, or the days preceding the release of financial statements and the Event Window, or the days following the release of financial statements.

As displayed in Figure 2, the timeline for the release of financial results communicated in an earnings announcement spans from negative 120 days (-120) to positive 3 days $(+3)$. The value 0 represents the date of financial release while 3 represent the 3 days before the release and +3 represents the 3 days following the release. The three dates preceding the financial release is called the "Estimation Period" while the three days following the release is called the "Event Window." In determining, an "event window" there is no recognized standard. Three days was used based on previous research by Boylan and Boylan (2017). Lyle et al. (2019) also determined investors are slow to respond to announcements and the benefits of earnings releases. They too found abnormal volatility happened in roughly three days following the announcement (Lyle et al., 2019). 
Given that the "event window" involved has a short time horizon, researchers chose to engage a short horizon liquidity beta to match this time frame. Based on research by Kamara et al. (2018), aligning the "event window" with a shorthorizon beta better quantifies the impact of the time horizon on risk.

\subsection{Sample}

Different industries have different Twitter use rates. When looking at the Twitter accounts by industry, the banking industry has the highest penetration rate at $94 \%$. Other high use industries include food products $(93 \%)$, retailers $(91 \%)$, chemicals (87\%), telecommunications (82\%), and utilities (73\%) (Internet Live Stats, 2020).

Ironically, little research exists on the highest group of users, commercial banks. There are several studies on food, retail, telecommunications, and utility companies (Barnes et al., 2013). Twitter was selected for this research for many reasons. First, it has the highest penetration rate of all the media in both corporate and the banking industry ( $\mathrm{Li} \& \mathrm{Li}, 2014$ ). Second, it is believed the penetration rate has little room for growth and thus less chance for significant change. Third, there was no significant peer-reviewed or professional literature on the industry's use of Twitter. Fourth, the platform has a near-real-time ability to publish information.

Researchers used several data banks to compile information. These data banks included the Federal Deposit Insurance Company, Federal Reserve Bank of Chicago, and the Consumer Federation of America. The data from the FDIC was verified by reviewing SM feeds, ticker symbols, the beginning stock price and the stock price after the event. Data confirmation was labor-intensive, while the calculations were straightforward.

Financial institutions were selected using several criteria. First, the institution had to be based in the United States and subject to American laws and regulatory requirements. Second, the bank needed to be ranked in the top 300 in size based on deposit assets. Third, the organization had to use Twitter to disseminate financials for the reporting period and have at least 1,000 followers. Fourth the institution had to be a public company and traded on either the NYSE or NASDAQ with a share price above $\$ 5$. Fifth the organization must have met the first four criteria for the four quarters of the study. Last, each MD\&A had to 
consist of at least 250 words, excluding titles and descriptions of charts or statements. Banks in the sample spread geographically throughout the country.

Several banks were eliminated from consideration. From the original threehundred largest banks reported, 147 were disqualified for various reasons: they were foreign banks, mutual or private banks, the banks were not traded on the NYSE or NASDAQ, the banks either went out of business or were delisted, the organizations had missions not focused on financial products like a labor union or a technology company, or they lacked followers on their Twitter site. In addition, Citigroup was eliminated because of the large volume of Tweets on its site. This organization could have upwards of two hundred Tweets a day, making it unlikely that an investor would use the site for financial information.

Researchers found seventeen banks meeting the established criteria and monitored the companies for the entire year. Researchers used the standard margin of error of $5 \%$ or 0.05 . The sample size consists of seventeen organizations using Twitter and seventeen similar-sized companies that did not. Each of these companies had four quarterly observations, meaning the sample size is 136 . This sample exceeds the thirty needed in a sample size for a normal distribution assumption.

\subsection{Procedure}

This study used the close-to-close stock pricing. This means stock prices were recorded at the close of both the day and the prior day to arrive at the change. Data on stock price and company beta ratio were needed to complete this analysis. Researchers obtained stock price from Measuringworth.com while beta came from Yahoo!Finance.com. The formula researchers used to calculate stock price increase is as follows:

$$
R_{d}=\frac{p_{d}-p_{d-1}}{p_{d-1}}
$$

Notation:

$\mathrm{R}_{\mathrm{d}}=$ Daily Return

$\mathrm{P}_{\mathrm{d}}=$ Closing price of stock for the day

$\mathrm{P}_{\mathrm{d}-1}=$ Closing price of stock for the prior day

This formula calculates Daily Return $\left(\mathrm{R}_{\mathrm{d}}\right)$. The numerator measures stock price at the close of the day minus the stock price for the prior day. The closing stock 
price for the prior day comprises the denominator. $\mathrm{R}_{\mathrm{d}}$ is the percent increase between the days' closing prices (Boylan \& Boylan, 2017) which is compared to the expected return as determined using the company's beta ratio.

Accounting researchers use an impact methodology called CARs in determining event relevance. This CARs model builds on the actual returns as a reference market and correlating the firm's stock price with a reference market. CARs comprise several items. First, CARs incorporates abnormal returns, normal returns, change, and the cumulative nature of the change. The formula for CARs comparing organizations using Twitter and organizations not using Twitter represents one for the three days preceding the Twitter release and the three days following the release is the aggregate of each data sets stock. The cumulative abnormal return (CAR) from time $\tau_{1}$ to $\tau_{2}$ is the sum of the abnormal returns (Williamson, 2020):

$$
C A R\left(T_{1}, T_{2}\right)=\sum_{T=T_{1}}^{T_{2}} \overline{A R}_{T}
$$

Notation:

$\mathrm{CAR}=$ Cumulative Abnormal Return

$\mathrm{AR}=$ Aggregate Return

$13610-\mathrm{K}$ and 10-Q statements were gathered from a common databank: The SEC's Electronic Data Gathering, Analysis, and Retrieval (EDGAR) system, over the period of December 2014 - November 2015. No amended returns were included in the sample. These amended returns happen after the filing date and would not have impacted stock price on the trigger date.

Researchers analyzed that each $10-\mathrm{K}$ document and used steps that involved cutting out a major portion of the Form 10-K or Form 10-Q. First, the entire Form 10-K or Form 10-Q was obtained. Second, the MD\&A section was separated from the original document and saved separately as Word files. Third non-word items and characters were removed from text including tables, charts, graphs, financial statements, acronyms, bullet points, underlining, headers, footers, page numbers, URLs, and websites. The characters included: the following items: “,”, “., “”,, “,”, “.”, “"”, “”,, “\$”, “\%,” “\&”, “(“, “)”, “-“. The remaining text was then submitted to the analysis tool to determine word strength. 


\subsection{Data Analysis}

A t-test was used to test the hypothesis. This was done to determine if the two sets of data, Twitter verses non-Twitter were statistically different. The t-test was done four times for each hypothesis. These included Twitter verses non-Twitter based on the sentiment of the MD\&A using Soper Sentiment Analyzer, and based on the sentiment of the MD\&A using Sentiment32 Sentiment Dictionary.

Extreme values were allowed to remain in the data, although it is normally excluded. The reason is these outlying pieces of data can cause changes in findings because of their extreme nature. The reason for this policy is to be meaningful and applicable in practice. This applicability needs to ensure the sample best represents the general population. Extreme cases exist in the stock market and one of the largest concerns for the average investor is how to deal with those extreme cases. Though most extreme cases that concern average investors is a result of negative information; the researchers believe that individuals deserve to know the research as it exists, not based on researcher convenience or for researcher benefit.

Two sentiment dictionaries were selected for this research: the Soper Sentiment Analyzer and the Sentiment32 Sentiment Dictionary. The Soper Sentiment Analyzer is a computational text mining program that determines the value of a communication. The analyzer is a general-purpose tool, which means it is not specific to any professional domain such as business, religion, or politics. The program is based on over 8,000 American National Corpus writing samples from various genres and domains. Each document analyzed garners a sentiment score. The design of the Soper Sentiment Analyzer produces a strong modern language analyzer focusing on American English communications after 1990 (Danielsoper, 2019).

The Soper Sentiment Analyzer was selected for its many advantages. First, the area of expertise including mental models, cognitive biases, linguistics, and decision support systems makes this model ideal for this research. Second, the software is free. Third, the ease of use allowed for documents to be analyzed in a timely manner. Fourth, the results were clear. The software uses three possible assessments: positive, neutral, and negative. This was considered advantageous given the options an investor has on their stock: buy, do nothing, or sell. "Buy" 
would represent the "positive" sentiment. "Do nothing" would represent a "neutral" sentiment. "Sell" would represent a "negative" sentiment.

The Sentiment32 is a common language sentiment analysis tool. The tool compares a set of prelabeled IMDb movie reviews to both individual words and short sequences of words. These are phrases that may be interpreted differently based on connotations rather than based on a denotation. For example, the phrase "not bad" is rated positively even though both words individually are negative (IMDb, 2016).

The Sentiment32 Sentiment Dictionary also has many advantages. This analysis tool has a broad range of available balances. The range is from positive onehundred for sentiment viewed favorably and negative one-hundred for sentiment viewed poorly. This range is considered an advantageous tool as, instead of having three possibilities, there are 201 (Sentiment32, 2019). This provides a larger dispersion. The dispersion permits extreme communications. Another advantage of the Sentiment32 tool is the tool utilizes common production theater language. This shows the appeal to average Americans, which is the type of average investor this study represents (Sentiment32, 2019).

The null and alternative hypotheses were analyzed using the statistical program SAS. SAS was selected due to the program being geared toward power users and its common acceptance among researchers. A further drill-down analysis was completed using analytics available in Excel. The reason for this analysis was to provide an individualized detail not available on SAS.

\section{FINDINGS}

The findings section provides the results of the research analysis. This is completed by first reviewing the key items necessary in the data collection process, then by analyzing the data from both a descriptive statistics standpoint using the Program SAS, and then a further drill down analysis using analytics in Excel. The data output is first itemized using the Twitter verses non-Twitter comparison using MD\&As as the basis for the data. This is followed by an analysis of MD\&As based on semantic analysis. The semantic analysis is completed using two different sentiment dictionaries: Sentiment Analyzer and the Senitiment32 Sentiment Dictionary. 
These dictionaries were used because of their focus on language commonly used by the general public. The Soper Sentiment used a format of: positive, neutral, and negative sentiment, represented in this data as a 1 for positive, 0 for neutral, and 1 for negative. The Sentiment32 dictionary uses a common language found in films. By using language popular in movie theaters, the data ensures a language most of the population can understand. The values in this dictionary range from 100 for a negative sentiment to a 100 for a positive sentiment.

Twitter vs. Non-Twitter Based on Soper Sentiment Analyzers

The descriptive statistics comparing the use of Twitter verses non-Twitter with an index based on Soper Sentiment Analyzer using SAS output are included in Table 1.

\begin{tabular}{lccccc}
\hline Quarter/Variable & $\begin{array}{c}\text { Mean Twitter } \\
\text { (no) }\end{array}$ & $\begin{array}{c}\text { Mean Non- } \\
\text { Twitter (yes) }\end{array}$ & Difference & t-Value & F-Value \\
\hline $4^{\text {th }} \mathrm{Q} 2014$ & -1.0647 & -15.6706 & 14.6059 & 0.2257 & 0.5617 \\
$1^{\text {st }} \mathrm{Q} 2015$ & -2.9294 & -3.0882 & 0.1588 & 0.9868 & 0.1772 \\
$2^{\text {nd }} \mathrm{Q} 2015$ & -1.4059 & 11.4529 & -12.8588 & 0.2546 & 0.6743 \\
$3^{\text {rd }} \mathrm{Q} 2015$ & 1.3529 & -10.0000 & 11.3529 & 0.2401 & 0.0131 \\
Total & -1.0118 & -4.3265 & 3.3147 & 0.6385 & 0.5086 \\
\hline
\end{tabular}

Table 1. Descriptive Statistics of Twitter versus Non-Twitter Using Soper Sentiment Analyzer

This table compares Twitter to Non-Twitter for Total Period for CAR in Excess of Beta Based on Soper Sentiment Analyzer.

From Table 1, significant data is available. In the "Total" category the mean CAR in excess of beta for banks using Twitter is -1.0118 . Alternatively, for banks not using Twitter the mean is -4.3265 . The difference is 3.3147 . The $t$-value is 0.6385 , which is higher than the 0.05 required to "fail to reject" the null. Additionally, the F-value is 0.5086. Like the t-value, this too is higher than 0.05. The F-value shows the variances between the two data sets of Twitter and non-Twitter. This shows a "fail to reject" standard has not been met. This means there is not enough evidence available to suggest the null hypothesis is false within a $95 \%$ confidence level. In other words, this means, overall, there is no significant difference between the banks that use Twitter to disseminate financial results and the banks that do not use Twitter to disseminate when applying the Soper Sentiment Analyzer. These results were consistent in "4th $Q$ 2014," "1 ${ }^{\text {st }} Q 2015$," and " $2^{\text {nd }} Q$ 2015." Only in " $3^{\text {rd }}$ Q 2015" did the values reflect a "justified in rejecting" standard being met. 
The distribution of both Twitter users and non-Twitter users taking into account the analysis using the Soper Sentiment Analyzer of the MD\&A is similar. There is little difference from a normal and a Kernel density distribution. This suggests a better sample, either larger or more accurate, would benefit the research. In fact, the variances significantly overlap and almost match. The Q-Q plot shows the two sets of data to be similar providing a "goodness of fit."

Since the results garnered a "failure to reject" the null hypothesis, there was no possibility of incurring either a Type I or Type II error. The results were well outside the $95 \%$ confidence, so no further testing was completed.

\begin{tabular}{lcccccc}
\hline TwitterNO & $\mathrm{N}$ & Mean & Std Dev & Std Err & Minimum & Maximum \\
\hline no & 17 & -1.0647 & 31.8450 & 7.7236 & -51.1000 & 47.9000 \\
yes & 17 & -15.6706 & 36.9112 & 8.9523 & -68.6000 & 75.8000 \\
Diff(1-2) & & 14.6059 & 34.4713 & 11.8236 & & \\
\hline
\end{tabular}

Table 2. The SAS output for the Soper Sentiment Analyzer

Table 2 shows the total mean sentiment for all four time periods using the Soper Sentiment Analyzer. This figure shows that there is a difference in the sentiment used by banks. The Twitter disseminators, on average, used less dramatic language (-1.0647) compared to the non-Twitter disseminators (-15.6706).

The descriptive statistics comparing the usage of Twitter verses non-Twitter with an index based on Soper Sentiment Analyzer using Excel analytics are included in Table 3.

\begin{tabular}{lcc}
\hline \multicolumn{1}{c}{ Quarter/Variable } & Mean Twitter (no) & Mean Non-Twitter (yes) \\
\hline $4^{\text {th }} \mathrm{Q} 2014$ & -1.1 & -15.7 \\
$1^{\text {st }} \mathrm{Q} 2015$ & -2.9 & -3.1 \\
$2^{\text {nd }} \mathrm{Q} 2015$ & -1.4 & 11.45 \\
$3^{\text {rd }}$ Q 2015 & 1.35 & -10.00 \\
Total & -.055 & -2.33 \\
\hline
\end{tabular}

Table 3. Twitter Total Period Comparing Mean Prior and Post “Trigger Event” Using the Soper Sentiment Analyzer

The data shows banks that do not release results on Twitter used stronger sentiment as measured by the Soper Sentiment Analyzer than banks that do. This is contrary to the knowledge that Twitter banks stock outperformed non-Twitter banks. On average the non-Twitter banks used a ranked sentiment of -2.33 compared to Twitter banks ranking of -0.55 . It is interesting to note that the average sentiment was negative while stock performance was positive. 
In the $4^{\text {th }}$ quarter of 2014 non-Twitter banks used an average sentiment ranking of -15.7 compared to -1.1 for Twitter disseminating banks. In the first quarter of 2015 , non-Twitter banks outperformed Twitter banks -3.1 to -2.9 . The $2^{\text {nd }}$ quarter were 11.45 to -1.4 . Results for the $3^{\text {rd }}$ quarter are -10.00 to 1.35 . In general, the non-Twitter banks had a larger variance in rankings. This means their high values were always higher and their lower rankings were lower.

\section{Twitter vs. Non-Twitter Based on Sentiment32 Semantic Analysis}

This section looks at the data on the Twitter vs. non-Twitter comparison using the Sentiment32 Dictionary for sentiment analysis. The descriptive statistics comparing the use of Twitter verses non-Twitter with an index based on Sentiment32 Sentiment Dictionary using SAS output are included in Table 4.

\begin{tabular}{lccccc}
\hline Quarter/Variable & $\begin{array}{c}\text { Mean Twitter } \\
\text { (no) }\end{array}$ & $\begin{array}{c}\text { Mean Non- } \\
\text { Twitter (yes) }\end{array}$ & Difference & t-Value & F-Value \\
\hline $4^{\text {th }} \mathrm{Q} 2014$ & 0.1765 & 0.1765 & 0.0000 & 1.0000 & 1.0000 \\
$1^{\text {st }}$ Q 2015 & 0.1175 & 0.8235 & -0.7059 & 0.0144 & 0.0161 \\
$2^{\text {nd }}$ Q 2015 & 0.2941 & 0.7059 & -0.4118 & 0.1670 & 0.1584 \\
$3^{\text {rd }}$ Q 2015 & 0.3529 & 0.2941 & 0.0588 & 0.8592 & 0.8253 \\
Total & 0.9412 & 2.0000 & -1.0588 & 0.1101 & 0.1185 \\
\hline
\end{tabular}

Table 4. Descriptive Statistics of Twitter versus Non-Twitter Using Sentiment32 Sentiment Dictionary

From this table, significant data is available. In the "Total" category the mean CAR in excess of beta for banks using Twitter is 0.9412. Alternatively, for banks not using Twitter the mean is 2.0000 , giving a difference of -1.0588 . The t-value of 0.1101 and F-value of 0.1185 are both higher than the 0.05 required to "fail to reject" the null. The F-value shows the variances between the two data sets of Twitter and non-Twitter and shows a "fail to reject" standard is not met. This means the research "failed to reject" the null hypothesis. Similar to the analysis of banks using the Soper Sentiment Analyzer, there is not enough evidence available to suggest the null hypothesis is false within a $95 \%$ confidence level. In other words, this means, overall, there is no significant difference between the banks that use Twitter to disseminate financial results and the banks that do not use Twitter to disseminate when applying the Sentiment32 Sentiment Dictionary. These results were consistent in " $4^{\text {th }} Q 2014$," " $2^{\text {nd }} Q 2015$," and " $3^{\text {rd }} Q 2$ 2015." Only in " $1{ }^{\text {st }} \mathrm{Q} 2015$ " did the values reflect a "justified in rejecting" standard being met. 
There is little difference from a normal and a Kernel density distribution. The Q-Q plot shows the two sets of data to be similar, providing a "goodness of fit." This suggests a better sample, either larger or more accurate, would benefit the research. The distribution of both Twitter users and non-Twitter users, taking into account the analysis using the Sentiment32 Sentiment Dictionary, is bimodal. This includes values near " -1 " and "+1." This shows the impact of the "thumbs up" and "thumbs down" methodology. The value of the "positive one" represents a "thumbs up" while the "negative one" represents a "thumbs down." There is also a low likelihood of a normal distribution. Since the sample, or n, was higher than the standard third for a normal distribution, the data was assumed normally distributed.

\begin{tabular}{lcccccc}
\hline TwitterNO & $\mathrm{N}$ & \multicolumn{1}{c}{ Mean } & Std Dev & Std Err & Minimum & Maximum \\
\hline no & 17 & 0.9412 & 1.4778 & 0.3584 & -1.0000 & 4.0000 \\
yes & 17 & 2.0000 & 2.2079 & 0.5355 & -3.0000 & 4.0000 \\
Diff (1-2) & & -1.0588 & 1.8787 & 0.6444 & & \\
\hline
\end{tabular}

Table 5. Shows the SAS output for the Sentiment32 Sentiment Dictionary

Table 5 shows the total mean sentiment for all four time periods using Sentiment32 Sentiment Dictionary. This figure shows the there is a difference in the sentiment used by banks. The Twitter disseminators, on average, used less dramatic language (0.9412) to the non-Twitter disseminators (2.0000). The descriptive statistics comparing the use of Twitter verses non-Twitter with an index based on Sentiment32 Sentiment Dictionary using Excel analytics are included in Table 6 .

\begin{tabular}{lcc}
\hline Quarter/Variable & Mean Twitter (no) & Mean Non-Twitter (yes) \\
\hline $4^{\text {th }}$ Q 2014 & 0.18 & 0.18 \\
$1^{\text {st }}$ Q 2015 & 0.12 & 0.82 \\
$2^{\text {nd }}$ Q 2015 & 0.29 & 0.71 \\
$3^{\text {rd }}$ Q 2015 & 0.35 & 0.29 \\
Total & 0.24 & 0.50 \\
\hline
\end{tabular}

Table 6. Twitter Total Period Comparing Mean Prior and Post "Trigger Event" Using the Sentiment32 Sentiment Dictionary

The data shows that banks who release results on non-Twitter banks used stronger sentiment as measured by the Sentiment32 Sentiment Dictionary than Twitter banks. These results were similar to the data from the Soper Sentiment Analyzer. This condition occurred in two of the four quarters. On average, the non-Twitter banks used a ranked sentiment of 0.50 compared with Twitter banks ranking of 
0.24. It is interesting that the average sentiment was negative while stock performance was positive. This contrasted the Soper Sentiment Analyzer, which recorded negative sentiment.

The non-Twitter banks were higher in the $1^{\text {st }}$ and $2^{\text {nd }}$ quarters with rankings of 0.82 and 0.71 . To the contrary, Twitter banks for the same quarters had rankings of 0.12 and 0.29 . In one quarter, the two sets of banks had the same sentiment value of 0.18. In the 4th quarter of 2014, the Twitter banks ranked higher than the non-Twitter banks with a score of 0.35 compared to 0.29 for non-Twitter banks. In general, like with the Soper Sentiment Analyzer, the non-Twitter banks had a larger variance in rankings. This means their high values were always higher, and their lower rankings were lower.

\section{CONCLUSIONS AND FUTURE RESEARCH}

This research combines financial needs and technology applications, using semantic analysis an examination of the relationship between publicly traded American banks and their use of Twitter to disseminate financial results. The MD\&A was extracted from the Forms $10-\mathrm{K}$ and 10-Q and semantically analyzed. This study answered the following question: "Can MD\&A word choice increase the stock price of American publicly traded banks using Twitter?"

There are many reasons why banks have not voluntarily started to disseminate financial information through social media including: lack of understanding RegFD, lack of technology adoption, and a lack of requests from investors. The lack of understanding RegFD involves many aspects of the organization. Unfortunately, policy is made more by following and mimicking competitors rather than seeking consultation from an expert.

The data in this case provided support to "fail to reject" the null hypothesis for both the Soper Sentiment Analyzer and the Senitiment32 Sentiment Dictionary. In this case, sentiment did not impact the share price of a stock. This research required a rigorous analysis of both technological knowledge and accounting principles. When considering the data for the entire reporting period, using the tValue and the F-Value as a guide, there was not a significant difference in the data to determine if sentiment was effective in helping increase the stock price. In fact, the values for both the t-Value and the F-Value were significantly higher than the standard benchmark of 0.05 to reject the null hypothesis. 
From Table 2, it can be seen that the word strength used is different between the groups. Non-Twitter dissemination banks used words with significantly less power (-1.0647), while Twitter banks used significantly stronger words (15.6706). In fact, the language used by both groups was more negative than positive. Table 5 confirms the word strength findings from Table 2; Twitter dissemination banks used words with significantly more power (0.5294), while non-Twitter banks used significantly weaker words $(0.1765)$. This is surprising that the given stock prices had a large increase over this research period.

This research has several recommendations for banks: the SEC should clarify rules including language requirements, banks should employ a social media strategy even if there are no immediate benefits, organizations should determine the best manner to disseminate information, and companies should extend their social responsibility policy to include fair disclosure.

First, the SEC should clarify rules and language requirements related to fair disclosure and provide implementation guidelines for organizations under their watch. Currently, the SEC gives very general guidelines for disclosure and leaves the implementation up to the organization. By providing greater detail on how organizations might disseminate information, the SEC will encourage more organizations to disclose, using social media while reducing the possible risk inhibiting organizations from implementation.

Second, banks should employ a dissemination strategy involving social media. Using the framework of the law outlined in the Literature Review, banks can, with little risk, add an additional step to their earnings release process. Once incorporated, this practice will become commonplace for both the organization and the investor. This would achieve several desired advantages and include little investment. First, even if the results do not support increased stock price today, it is difficult to determine when they might. Organizations adopting a dissemination policy early will benefit from the compounded impact, even if the increase is small in the beginning. Failure to adopt a dissemination policy, however, would be to the detriment of shareholders. Here word choice is less important than the benefits of dissemination.

Third, banks need to determine the best department in the organization to disseminate and the best procedure. Today, confusion looms about what department of the organization is best suited to communicate. Investor relations, 
marketing, accounting, and social media are all involved in the dissemination process. The dissemination process should follow a specific and concise timeline.

Today it is common for an organization to have a live earnings call. Immediately following the earning meeting, the communication of financial results should be sent out to all media sources at the same time. Currently some of these outlets include: Bloomberg, the New York Times, and the company's web site. This recommendation involves adding several social media outlets such as Facebook, WhatsApp, WeChat, QZone, and Twitter to those pre-determined outlets.

Fourth, banks should use the dissemination of financial results as an extension of their social responsibility policy. Banks are under extensive government regulation and often voluntarily adopt additional social responsibility policies. Reinforcing the concept of fair disclosure as a part of social responsibility can only work to solidify a bank's commitment to the communities and investors they serve. Given there is no evidence dissemination does harm, this action will only be advantageous to the organization.

This study had several limitations: Twitter only has a 280-character capacity per Tweet, forcing communicators to use links rather than live information; this study has only two statistical analyzers; technology tracking disseminated message and user reaction was unavailable; beta was pulled at the time of research rather than at the time of dissemination; and with any stock price study, world or corporate events unrelated to this study may have affected share price.

Semantics and social media use are both new and growing. At present, too few banks are disseminating using Twitter, and too few investors are following those Twitter pages. This is only more reason to study this field as it has a great deal of opportunities for future research and should proceed full steam ahead. These opportunities include using different sentiment analyzers, analyzing the earnings release itself, analyzing investors dissemination needs, or looking at specific national economic events impacting results. 


\section{REFERENCES}

Adams, C. (2017). Understanding Integrated Reporting, London: Routledge, http://doi.org/10.4324/9781351275002.

Alexander, R. M., \& Gentry, J. K. (2014). Using social media to report financial Results. Business Horizons, 57(2), 161-167. https://doi.org/10.1016/j.bushor. 2013.10.009.

Aureli, S. (2017). A comparison of content analysis usage and text mining in CSR corporate disclosure. The International Journal of Digital Accounting Research, 17, 1-32. http://doi.org/10.4192/1577-8517-v17_1.

Berger, P. G. (2011). Challenges and opportunities in disclosure research - A discussion of 'the financial reporting environment: Review of the recent literature. Journal of Accounting and Economics, 51(1), 204-218. http://doi.org/ 10.1016/j.jacceco.2011.01.001.

Blankespoor, E., Miller, G. S., \& White, H. D. (2014). The role of dissemination in market liquidity: Evidence from firms' use of Twitter. The Accounting Review, 89(1), 79-112. http://doi.org/10.2308/accr-50576.

Bollen, J., Mao, H., \& Zeng, X. (2011). Twitter mood predicts the stock market. Journal of Computational Science, 2(1), 1-8. http://doi.org/10.1016/j.jocs. 2010.12.007.

Boylan, D. H. (2016). The innovative use of Twitter technology by bank leadership to enhance shareholder value. ProQuest.

Boylan, D. H., \& Boylan, C. L. (2017). Technology in accounting: Social media as an effective platform for financial disclosures. The International Journal of Digital Accounting Research, 17, 93-109. http://doi.org/10.4192/1577-8517v17_4.

Charlier, M. (2013). Social media: Cause for pause. IR update, 9, 7-10.

Cliff, D., Brown, D., \& Treleaven, P. (2011). Technology trends in the financial markets: A 2020 vision. UK Government Office for Science.

Cwynar, A., Cwynar, W., Pater, R., \& Kilipek, K. (2019). Social media as an information source in finance: Evidence from the community of financial market professionals in Poland. The International Journal of Digital Accounting Research, 19, 29-58. http://doi.org/10.4192/1577-8517-v19_2.

Danielsoper.com. (2019). Retrieved January 08, 2019, from http://www.daniels oper. com/. 
Feldman, R., Givindaraj, S., Livnat, J., \& Sigal, B. (2010). Management's tone change, post earnings announcement drift and accruals. Review of Accounting Studies, 15(4), 915-953. http://doi.org/10.2139/ssrn.1287083.

Firth, M., Wang, K., \& Wang, S. (2015). Corporate transparency and the impact of investor sentiment on stock prices. Management Science. 61(7), 1630-1647.

Groyberg, B., \& Slind, M. (2012). Leadership is conversation. Harvard Business Review, 90(6), 76-84.

IMDb. (2016). Internet bookseller Amazon.com announces acquisition of United Kingdom company the Internet Movie Database Ltd. IMDb via PR Newswire Europe, Retrieved January 19, 2019.

Internet Live Stats. (2020). Twitter usage statistics. Retrieved from https://www.internetlivestats.com/

Jiang, Y. (2011). Investor sentiment and stock market response to earnings announcement. Management and Service Science, 2011 International Conference, $1-4$.

Johnson, J., \& Grimm, P. E. (2010). Communal and exchange relationship perceptions as separate constructs and their role in motivations to donate. Journal of Consumer Psychology, 20(3), 282-294. http://doi.org/10.1016/j.jcps. 2010.06.018.

Jowett, B. (1875). The dialogues of Plato Volume V (2nd ed). Oxford: Clarendon Press.

Jung, M. J., Naughton, J. P., Tahoun, A., \& Wang, C. (2018). Do firms strategically disseminate? Evidence from corporate use of social media. The Accounting Review, 93(4), 225-252. http://doi.org/10.2308/accr-51906.

Kamara, A., Korajczyk, R. A., Lou, X., \& Sadka, R. (2018). Short-Horizon Beta or Long-Horizon Alpha? Journal of Portfolio Management, 45(1), 96-105. http://doi.org/ 10.2139/ssrn.2890944.

Kivimaa, P., \& Kern, F. (2016). Creative destruction or mere niche support? Innovation policy mixes for sustainability transitions. Research Policy, 45(1), 205-217. http://doi.org/10.1016/j.respol.2015.09.008.

Li, X., Xie, H., Chen, L., Wang, J., \& Deng, X. (2014). News impact on stock price return via sentiment analysis. Knowledge-Based Systems, 69, 14-23. http://doi.org/10.1016/j.knosys.2014.04.022.

Li, Z., \& Li, C. (2014). Tweet or "re-tweet"? An experiment of message strategy and interactivity on Twitter. Internet Research, 24(5), 648-667. http://doi.org/10.1108/IntR-11-2013-0233. 
Liu, B. (2012). Sentiment analysis and opinion mining, San Rafael, California: Morgan \& Claypool Publishers. ISBN: 9781608458844.

Lyle, M. R., Rigsby, C., Stephen, A., \& Yohn, T. L., The Speed of the Market Reaction to Pre-Open versus Post-Close Earnings Announcements (May 9, 2019): Kelley School of Business Research Paper No. 17-75, http://doi.org/ 10.2139/ssrn.3064160.

Loughran, T., \& McDonald, B. (2014). Measuring readability in financial disclosures. The Journal of Finance, 69(4), 1643-1671. http://doi.org/10.1111/ jofi.12162.

Loughran, T., \& McDonald, B. (2011). When is a liability not a liability? Textual analysis, dictionaries, and 10-Ks. Journal of Finance, 66(1), 35-65. https://doi.org/10.1111/j.1540-6261.2010.01625.x.

Luftman, J., Lyytinen, K., \& Zvi, T. (2017). Enhancing the measurement of information technology (IT) business alignment and its influence on company performance. Journal of Information Technology, 32(1), 26-46. http://doi.org/10.1057/jit.2015.23.

Menkveld, A. J. (2011). Electronic trading and market structure. UK Government Office for Science.

Morgan, J. D. (2013). SEC permits social media use for corporate disclosure, National Investor Relations Institute, April. Available at: http://www.niri.org/Main-Menu-Category/resource/publications/ ExecutiveAlert/2013-Executive-Alert-Archive/SEC-Permits-Social-Media-Use-forCorporate-Disclosure-.aspx.

Narayanan, V., Arora, I., \& Bhatia, A. (2013). Fast and accurate sentiment classification using an enhanced Naïve Bayes model. Lecture Notes in Computer Science. 1-7.

Ogneva, M. (2010, April 19). How companies can use sentiment analysis to improve their business, Retrieved from ttp://mashable.com/search/?utf8=|\%E2 $\backslash$ $\% 9 \mathrm{C} \backslash \% 93 \backslash \& \mathrm{q}=$ how + companies + can + use + sentiment + analysis + to + improve + their +business $\backslash \&$ commit $=$ Search.

Orlitzky, M., Schmidt, F. L., \& Rynes, S. L. (2003). Corporate social and financial performance: A meta-analysis. Organized Studies, 24(3), 403-441. http://doi.org/10.1177/0170840603024003910.

Rango, G., Aleksovski, D., Caldarelli, G., Grcar, M., \& Mozetic, I. (2015). The effects of Twitter sentiment on stock price returns. PLoS ONE, 10(9), e0138441. http://doi.org/10.1371/journal.pone.0138441. 
Schumaker, R. P., \& Chen, H. (2009). Textual analysis of stock market prediction using breaking financial news: The AZFinText system. ACM Transactions on Information Systems, 27(2), 12. http://doi.org/10.1145/1462198.1462204.

SEC Clarifies Social Media Use and Reg FD Compliance. (2013). Retrieved from:http://www.goodwinprocter.com/publications/newsletters/clientalert/2013/0.

Securities and Exchange Commission. (2013). Report of investigation pursuant to Section 21(a) of the Securities Exchange Act of 1934: Netflix, Inc., and Reed Hastings (Release No. 69279), Available at http://www.sec.gov.

Sentiment32. (2019). Retrieved January 10, 2019, from http://www.sentiment32. $\mathrm{com} /$.

Smailovic, J., Grcar, M., Lavrac, N., \& Žnidarsic, M. (2014). Stream-based active learning for sentiment analysis in the financial domain. Information Sciences, 285, 181-203. http://doi.org/10.1016/j.ins.2014.04.034.

Sprenger, T. O., Tumasjan, A., Sandner, P. G., \& Welpe, I. M. (2014). Tweets and trades: The information content of stock microblogs. European Financial Management, 20(5), 926-957. http://doi.org/10.1111/j.1468-036X.2013.12007.x

Taboada, M., Brooke, J., Tofiloski, M., Voll, K., \& Stede, M. (2011). LexiconBased Methods for Sentiment Analysis. Computational Linguistics, 37(2), 267307. http://doi.org/10.1162/COLI_a_00049.

Thelwall, M., Buckley, K., Paltoglou, G., Cai, D., \& Kappas, A. (2010). Sentiment strength detection in short informal text. Journal of the American Society for Information Science and Technology, 61(12), 2544-2558. http://doi.org/10.1002/asi.21416.

Thoring, A. (2011). Corporate tweeting: Analysing the use of Twitter as a marketing tool by UK trade publishers. Publishing Research Quarterly, 27(2), 141-158. http://doi.org/10.1007/s12109-011-9214-7.

Thornton, N. (2015, September 03): Is market volatility spooking 401(k) investors? Benefits Selling. Breaking News, 3.

Williamson, S. (2020). Daily Closing Value of the Dow Jones Average, 1885 to Present. MeasuringWorth.com, Retrieved January 09, 2020, from URL: http://www.measuringworth.com/DJA/

Wright, A. (2009). Mining the web for feelings, not facts, New York Times, B1. Retrieved from http://cacm.acm.org/news/38733 -mining-the-web-for-feelingsnot-facts/fulltext. 